\title{
The influence of responsible leadership on talent retention
}

\author{
Evangelia Fragouli \\ Masoud Alhaider \\ School of Business, University of Dundee, Dundee, UK
}

\section{Keywords}

Responsible Leadership, Talent Retention, Organisational Performance, Leadership.

\begin{abstract}
Recently, the relationship between responsible leadership and talent retention has been discussed in the literature. Retention of talent is perceived as a crucial component in an organisation's business strategy where employees become the key set of stakeholders. However, the particular practices that result in retaining the most effective employees, specifically young professionals, and new managers, remain difficult to pinpoint. The aim of this research is to study the relationship between responsible leadership and talent retention. Existing literature on the topic has been reviewed to address the objective of this research. The findings indicate that there is a close association between responsible leadership and talent retention. Responsible leadership encourages leaders to lead their followers in a way that enhances their connection with society, the environment, stakeholders and with the organisation generally. The findings of the study further reveal that responsible leadership does not just influence talent retention, it enables autonomous motivation amongst employees and improves the performance of the organisation as a whole.
\end{abstract}

\subsection{Introduction}

The idea of responsible leadership (RL) has gained interest across the diverse domains that comprise the field of organisational studies. Several corporate scandals that occurred in the past have highlighted the need to examine the ethics of organisations and the role of RL (Fernando, 2015). Major collapses in the corporate sector, the recall of products, and excesses indulged in by corporations have also given rise to the level of responsibility that we should expect from managerial leadership. Waldman and Galvin (2008) have suggested that the idea of responsibility has been lacking from descriptors of established leadership that typically include: charismatic, transformational, authentic, servant, participative spiritual, shared and ethical. Leaders are also under continual pressure to lead their followers in such a manner that they are responsible not just to the business organisation, but to the stakeholders as a whole. Maak and Pless (2006) defined RL as the procedure which results in the development and sustenance of affirmative associations with external as well as internal stakeholders of the organisation. Thus, RL is becoming a vital discourse within management and there has been an increase in appeals for leaders to act in a responsible manner within a business environment that has suffered a loss in terms of trust and legitimacy (Antunes \& Franco, 2016). The initial stages related to the development of RL concentrates on exploring and conceptualising the values of individuals and their individual encouragements.

Organisations as well as leaders within organisations are increasingly including a wider base of stakeholders within the decision-making and planning process. While it is evident that the literature pertaining to leadership is extensive, scholars have only recently attempted to integrate leadership, corporate responsibility, and ethics. As presented by Kapur (2018a), scholarship pertaining to ethics, leadership and corporate social responsibility has witnessed for the most part an independent evolution. Irrespective of the expanding literature related to effective leadership, there is a dearth of research focusing on the association between RL and turnover intentions. According to one definition of a leader, a leader is an individual who holds a key position within a group, makes an impact on others in tandem with the expectations of the work role related to that position, and directs and co-ordinates the group in sustaining itself while achieving its objective (Simiyu, 2015). More recently, a leader who is responsible has been defined as an individual who develops an inclusive culture that is developed on solid moral ground. In tandem with what several authors have to say about leaders, leadership can be perceived as a procedure of inclusion to realise group, societal and organisational objectives. This comprises the social- 
relational procedures of the individual managers and assorted activities that are determined within the upper levels of the organisation which is actively comprised of several stakeholders in order to function in a consistent manner as an organisation that is socially responsible and ethical (Kapur, 2018b).

Crises pertaining to governance and ethics witnessed during the first decade of the 21st century, and the relevant economic slowdowns during 2000-2002 and 2008-2010, have presented several challenges with regard to assumptions about the role of corporations within society and the very basis of the capitalist system (Aurifeille et al., 2011). Leaders within businesses have understandably emerged as targets facing extensive criticism and indeed were blamed for several economic and ethical failures during the period 2000-2009. Nonetheless, over the course of this period, certain organisations, along with their leaders, have attempted to adopt new management styles which are more inclusive and deemed to be pertinent and respectful to the requirements and well-being of a more extensive group of stakeholders. In this context, some scholars have scrutinised certain traits possessed by leaders and organisations under the aegis of RL (Cismas et al., 2016). Some researchers have claimed that it is imperative for leadership to integrate corporate responsibility, conscientious and conscious stakeholder relations and ethics (Owie, 2017). Employees are a vital group of stakeholders that have shouldered the costs associated with poor economic choices and questionable ethical decisions. Out of the primary groups of stakeholders employees, communities, shareholders, and suppliers - employees are the most crucial to business operation. The effectiveness of the management in protecting the well-being of employees, as well as the retention of the workforce within the organisation, is highly dependent on a responsible leader's behaviour (Flocy, 2017).

\subsection{Background}

Currently, scholars of RL are known to deploy less normative as well as subjective assumptions while concentrating on orientations of leadership and abilities instead of virtues (Miska \& Mendenhall, 2018). There have been some studies that have scrutinised the impact of RL on employees as well as organisational outcomes. For example, organisational commitment has been identified as a vital employee outcome which results in effective performance by the employees. The importance of organisational commitment has been extensively acknowledged within studies pertaining to leadership (Voegtlin et al., 2012), which demonstrates the impact of effective leadership on employee commitment. There exists an extensive body of literature that concentrates on the interlink between the workgroup and leaders, specifically pertaining to how diverse styles of leadership are associated with the degree of organisational commitment (Meyer et al., 2002). It has been argued that the behaviours displayed by managerial leadership are instrumental in defining the manner in which leaders set direction, motivate and align people while inspiring members within the organisation (Kotter, 1990). Simply put, the right type of leadership tends to nurture an environment that offers high commitment. Therefore, studies pertaining to diverse styles of leadership along with employees' organisational commitments suggest that responses in leadership are necessary to drive commitment from followers (Kim \& Brymer, 2011). The present challenge within the domain of leadership revolves around the ability to develop conditions within organisations that enhance organisational commitment towards the organisation. Several researchers have suggested that RL produces an affirmative influence on the organisational commitment of employees (Doh \& Quigley, 2014). It has also been suggested, that owing to a wide range of stakeholders within and beyond the organisation, RL could possibly have a positive impact on the level of organisational commitment towards the employees.

Considering that the concept of RL is interdisciplinary in nature, RL has drawn considerable attention from researchers from different domains including: human resource management, organisational behaviour, philosophy, strategy, political science, sustainability, psychology, corporate governance, law, sociology, marketing and business ethics (Siegel, 2014). Although the notion of RL is comparatively new within the extant literature, it reveals a substantial theoretical significance for organisational leadership. In particular, a large number of researchers have accepted and agreed that RL tends to innately intersect the group, individual and organisational levels of outcome in terms of leadership. The notion of RL can also incorporate two particular domains of study: leadership and social responsibility. Extensive literature exists with regards to social responsibility and its link with the financial outcomes of organisations. However, additional exploration is needed within employees as well 
as organisational outcomes (Rodriguez-Fernandez, 2016). In addition, RL enables an organisation to achieve group, societal and organisational goals to continuously operate in a socially responsible and ethical manner inside its business community (Doh et al., 2011). Therefore, it is evident that RL can be incorporated within both macro as well as micro-based literature on social responsibility. RL perceives leadership as a process or technique that promotes inclusion in order to integrate group, societal and organisational goals.

Furthermore, Waldman and Galvin (2008) showed that the idea of responsibility does not exist anymore in present leadership practices comprised of different leadership styles. RL encourages leaders to lead their followers in a manner that is responsible to society, the environment, and stakeholders as well as the organisation (Maritz et al., 2011). It also suggests that leaders lead in an environment of business where their legitimacy might be decreasing owing to the increasing prevalence of unethical acts within business, whereby all leaders can be 'tarred with the same brush' (Pless \& Maak, 2011). First, RL broadens the scope of the association between the leader and their followers for its global and social business objectives. Second, RL identifies moral and ethical dimensions that should be considered as normative in the relationship between the leader and their stakeholders (Maak \& Pless, 2006). It hints that the leader needs to be responsible which will allow them to be effective leaders. Third, RL provides an approach which is more balanced by encouraging leaders to be facilitators, resulting in more relational processes that, in turn, lead to stronger relationships between stakeholders and leaders. Therefore, the theoretical development, in terms of RL envisions an inclusive culture amongst societies and organisations by developing a robust moral ground for responsible businesses practices. However, the question here is whether the association between leadership and organisational commitment continues to function when employees conceal their intentions pertaining to turnover.

Retention of talent is considered as a sine qua non for realising a competitive edge within business. This is because turnover that occurs unexpectedly within an organisation negatively impacts on the survival and the profitability of the organisation (Mir \& Mufeed, 2016). Without having a RL, one thoroughly committed to a business strategy that tackles talent development and retention, the long-term viability of an organisation is challenged. Retention of talent is perceived as a vital component of an organisation's business strategy where employees become the key set of stakeholders. However, the particular practices that result in retaining the most effective employees, specifically young professionals and new managers, continues to evade several organisations (Guthridge et al., 2008). This challenge can be acutely experienced in markets that are dynamic and emerging. Keeping these factors in mind, the objective of this paper is to examine the relationship between RL and employee retention. In case there is any relation, an attempt will also be made to identify how RL influences employee retention.

\subsection{Research Aims \& Objectives}

The primary aim of this research is to understand whether RL is associated with talent retention. In order to facilitate this, the following research objectives and research questions have been framed.

\subsection{Research Objectives}

- To understand if there is an association between responsible leadership and talent retention.

- To explore the relationship between responsible leadership and employee autonomous motivation.

- To explore the relationship between talent retention and organisational performance.

\subsection{Research Questions}

What is the link between responsible leadership and talent retention?

What is the relationship between responsible leadership and employee autonomous motivation?

What is the link between talent retention and organisational performance?

\subsection{Literature review}

\subsection{Reviewing the concept of responsible leadership}

RL as a concept is essentially grounded in stakeholder theory (Antunes \& Franco, 2016). It has been operationalised from the viewpoint of employees and their perceptions related to the actions taken by leaders in order to create value within organisations (Doh et al., 2011). To date, many scholars (Waldman 
\& Balven, 2014; Witt \& Stahl, 2016) have attempted to explain why RL, as a normative leadership approach, is unique from various other value-centric leadership theories such as ethical leadership (Brown \& Treviño, 2006a), servant leadership (Greenleaf et al., 2002), authentic leadership (Gardner et al., 2005), and transformational leadership (Bass \& Avolio, 1994). As per Maak et al. (2016), the key variation between value-centric leadership and RL is the focus of the latter on creation of value which is sustainable through positive social changes. Therefore, RL can be considered from an ethical as well as relational dimension (Maak et al., 2016). Scholars have hinted that the study of RL requires a consideration of organisational viewpoints with regards to employee outcomes as well as antecedents (Stahl \& Sully de Luque, 2014).

The idea of RL has been conceptualised as a concept which is currently emerging at the intersection of studies related to leadership, ethics and corporate social responsibility (Miska \& Mendenhall, 2018). RL has been defined by Maak and Pless (2006) as an ethical and relational phenomenon that occurs in social procedures of interactions amongst those who impact or are impacted by leadership and have a stake in the vision and purpose of the relationship of leadership. RL is deemed to have a wider appeal compared to theories of ethical leadership. It is a process model of leadership indirectly related to the ethical traits of leaders. This kind of interpretation within a global context could present many restrictions. Such authors therefore conceptualise ethical traits as the antecedents of RL. From a wider perspective, RL embodies a notion that is known to exist at the intersection of two existing domains of study: leadership and social responsibility (Waldman \& Balven, 2014).

If RL is investigated from the perspective of organisations, essentially it would also be inclusive of any consideration of the behaviour of individuals, their decisions and their interrelations with influences of leadership (Waldman \& Balven, 2014). In the same vein, Voegtlin et al. (2012) observed that responsible leaders have an intrinsic role to play within organisations as role models and in including employees in decision-making. As an outcome, when employees are known to follow leaders who are responsible, there is the possibility that this will lead to increased motivation, job satisfaction, organisational citizenship or commitment. Many scholars have suggested that responsible leaders deem their followers as significant stakeholders to make use of their unique viewpoints in sustaining their creativity and motivation (Zhang \& Bartol, 2010). These authors have also observed that responsible leaders, at the level of individual teams, encourage and consider the various perspectives of stakeholders. This might result in psychological safety at the team level, learning for performance of the team and to enhance the process of decision-making.

The idea of RL has been undergoing continuous evolution; however, it is supposed to be tackled in a rather complete manner and should be clarified in terms of research and theory (Maak \& Pless, 2009). There have been many thought leaders, scholars, practitioners and academics who have attempted to define RL from their individual viewpoints within modern organisations (D'Amato et al., 2009). As a notion of leadership based on values, RL recognises the current gaps within the literature for leadership and also attempts to define what 'responsible' means from the setting of organisational leadership (Pless \& Maak, 2011). It has been argued that leadership cannot exist in the absence of matching responsibility for a result like RL. Likewise, it Waldman and Galvin (2008) have also argued that the idea of responsibility has been lacking within other theories of leadership that are value-based.

There is strong evidence that decisions, perceptions and the actions on the part of individual managers, specifically those who occupy senior positions, make an impact on the long-term viability and social performance (Kakabadse et al., 2005). For organisations, a leader is an individual who holds a specific position within a group, makes an impact on others in tandem with the role expectations of the position, and directs as well as coordinates the group for its maintenance and achieving its objectives. Furthermore, a leader who is responsible has been identified as one who develops an inclusive culture based on moral grounds (Pless \& Maak, 2004). Therefore, RL at the level of organisation is deemed as a procedure of inclusion to realise organisational, societal and group objectives. According to Phillips et al. (2003), the notion of RL is inclusive of the social-relational procedures of individual leaders and groups' organisational actions that have been defined by the upper levels which is actively comprised of diverse stakeholders in creating organisations that are socially and ethically responsible. Thus, RL concentrates on 
the individual initiative towards the goal of a society to enable the organisation to emerge as a responsible and ethical system overall.

If the societal viewpoint of RL is taken into account, Doh and Quigley (2014) have suggested that leaders who are in a position to continuously adhere to a stakeholder approach would be better facilitated to manage beyond cultural boundaries. The stakeholder perspective of leaders might also identify and anticipate vital socio-economic problems in trends of business such that they would be able to respond in a suitable manner (Stahl \& Sully de Luque, 2014). In addition, studies pertaining to corporate governance lay much stress on the fact that organisational leaders arrive at decisions of CSR strategies within the framework of mechanisms pertaining to organisational governance (Filatotchev, 2012). This could mould the base of accountability and responsibility in leadership not just for stakeholders but also to a broader body of stakeholders. Thus, from the organisational to the social level, Doh and Quigley (2014) have claimed that leaders who are responsible with a stakeholder approach would assist in developing an open, inclusive and diverse internal culture by disseminating and sharing information while nurturing robust associations with external stakeholder, all of which would result in performance, organisational growth and innovation (Thomas, 2004).

\subsection{Critically Reviewing the Concept of Talent Retention}

Retention is deemed an overall component of the tactics and strategies related to human resources. It commences with the selection of correct employees and continues with the execution of diverse programs to ensure that the employees remain motivated and are kept engaged within the organisation (Rasmussen \& Hunt, 2007; Das \& Baruah, 2013). At the same time, Das and Baruah (2013) have defined talent retention as a method which business organisations have adopted to sustain a workforce which is effective and matches their requirements from an operational point of view. Das and Baruah (2013) further explain talent retention as a procedure through which employees are kept motivated to serve an organisation for an extended period of time or till such time that their part or project reaches its culmination. According to Kossivi et al. (2016), talent retention is an approach which is systematic in nature and intended to create and nurture a work environment that stimulates employees within an organisation to stay employed, on the basis of practices and policies framed to tackle their diverse organisational requirements.

Cappelli (2008) notes that towards the end of 1990s, the problem of retaining talent emerged as a major challenge within business. This view was further extended by Allen et al. (2010) who argued that retention of employees is a vital concern for several organisations and managers within organisations. These authors claimed that retention related costs generally tend to extend beyond $100 \%$ of the annual salary for the position. In addition, talent (employee) retention has been outlined as an initiative by many organisations to sustain a work-based environment that supports present staff in continuing with the organisation. Several talent retentions police are focused at tackling the diverse requirements of employees to improve job satisfaction and reduce significant costs related to recruiting and training new staff. Moreover, with regards to the issue of talent retention, Chambers et al. (1998) have stated that relatively little awareness exists regarding the problem of talent retention, and that high performing individuals have high scope to quit the organisation.

'Talents on hold' is another term often used to denote talent retention. Cappelli (2008) described it as a process where talented employees are successfully retained by keeping them on hold in positions, they are highly qualified for. This could be due to the organisation not possessing adequate specialist or top positions for existing employees. This could encourage talented employees to leave their current organisation to seek employment with a competing organisation. Furthermore, talent can be equated with inventory that has the freedom to leave the organisation, and this situation takes place when an organisation develops a large number of talented employees in excess of what is required by the organisation (Cappelli, 2008). In contrast, the inadequate education of talent implies that the organisation would have to outsource the required talent. One potential disadvantage of outsourcing talent is that this procedure is resource and time consuming as it involves the recruitment of talent with high calibre. Additionally, many such prospective employees may be unsure about their capabilities and whether they can blend into the culture of the new organisation. 
Allen et al. (2010) also observed variations as well as misconceptions with regards to the reason why organisations are unable to retain talents. A common misconception is that talents often quit the organisation because it does not reward them appropriately. Nonetheless, researchers have deliberated that the most common reasons why talented employees quit an organisation is due to dissatisfaction with their peers and limited training and development options. Furthermore, Bartram (2012) highlighted the importance of encouraging future training and development well before the employee commences seeking better work opportunities. In addition, Bhattacharya et al. (2008) highlighted the significance of maintaining common values and goals amongst employees in the organisation in order to establish a stable association and encouragement to stay.

\subsection{The Role of Responsible Leadership on Talent Retention}

Maamari and Alameh (2016) stated that organisations that exist within several industries have identified skilled talent or human resources as crucial to achieve the objectives of the business. Congruently, Holtom et al. (2005) argued that organisations that concentrate on resources without paying attention to recruitment, training and retention are likely to struggle to survive in the highly competitive business market. Loss of employees in an unexpected manner and the subsequent effort to replace the lost talent is a major challenge to the resources of an organisation (Bandura \& Lyons, 2014). A possible way to tackle negative outcomes in business is to investigate organisation based behaviours that might impact upon talent retention (Low et al., 2017). Studies that have been conducted in recent years suggest the importance of widening the criterion related to research on talent retention, to assess the impact over time (Woo et al., 2016). Furthermore, the extant literature with regards to talent retention clearly implies that the ability of an individual tends to play a major role in the expectation to continue in a job, as organisations choose an individual with the appropriate qualification to cater to the job requirements (Ibidunni et al., 2016). Research has highlighted the key role played by leaders in making a positive influence on the decision of an employee to remain in a job. In addition, recent research has emphasised how 'person-fit' has proved helpful to researchers in comprehending how 'the most suitable person' who is thoroughly engrossed in their work might have less scope to voluntarily leave their present job (Jin et al., 2018).

According to Caldwell and Dixon (2010), the role of a leader within a business organisation is to accord due dignity and respect to their employees. Responsibility as well as accountability in terms of talent retention largely rests on the shoulders of leaders. Further, skills in leadership are instrumental in developing the environment that facilitates retention, the work environment and a culture which is supportive would be beneficial for employees which, in turn, will help them gain motivation. This is apparently the most suitable manner of defence against unnecessary attrition (Chitra, 2013). In instances when leaders or top management evince concern and interest, employees who gain frequent and positive feedback and recognition from their organisations and leaders are more interested in continuing in a job. Thus, he relationship between a leader and their employees can impact on the intention of the employee to remain in their work and serve the organisation. Likewise, Netswera et al. (2005) noted that in situations where the leaders are interested, this will make a positive impact on the level of employee retention.

In addition, it has been observed by Gwavuya (2011) that better relations between a responsible leader and their employees offers confirmation to a business enterprise that the employees within that enterprise will continue to stay for an extended period of time. However, when the association between the leader and the employees is not very good or poor, this can result in employee dissatisfaction to develop, leading to low levels of employee commitment which, in turn, incentivises the employee to think about quitting (Gwavuya, 2011). Several other studies have revealed that an affirmative association between employees and their leaders is significant in terms of augmenting employees' intention to continue working for the organisation (Cowin, 2002; Berson \& Linton, 2005; Northouse, 2018). In this regard, Berson and Linton (2005) suggested that better relations between leaders and their employees could result in low levels of employee intention to leave the organisation. Similarly, Northouse (2018) asserted that inappropriate or unimportant styles of leadership could have a direct negative impact on retention as well as the performance of employees in a modern organisation. While Kleinman (2004) has argued that leadership style is a key factor that enhances satisfaction in work and fosters talent retention, 
the empirical evidence is mixed. For example, Gharibvand et al. (2013) examined the relationship between leaders and employees. They found that the results were quite confusing as there was ambiguity wherein some employees were satisfied and committed to the job and others were not happy with the leadership style.

On the basis of the literature review, the main aim of this research is to understand whether responsible leaders influence talent retention within organisations.

\subsection{Methodology}

The research methodological approach adopted for this research is founded on a critical review of the existing literature. The objective of a literature review is to acquire an in-depth understanding of the research and consider debates that are pertinent to phenomenon under investigation (Snyder, 2019).

Developing research and linking it with existing information and knowledge is considered the building block of good academic research. Production of knowledge in the domain of business related research is increasing at a quick pace, and at the same time it continues to be both inter-disciplinary as well as segregated (Tranfield et al., 2003). This makes it difficult to keep up with state-of-the-art research and remain at the forefront, and at the same time evaluate the collection of evidence in a specific domain of research. This is primarily the reason why the use of literature review as a method of research is considered appropriate here. A literature review as a technique of research represents a systematic manner of gathering and synthesising information from extant research (Baumeister \& Leary, 1997).

In the context of this present research, the literature review approach was considered the most suitable in meeting the objectives of the current study as it facilitated gaining an in-depth insight into the manner in which researchers investigated the influence of responsible leaders on talent retention within organisations. Furthermore, it assisted in acquiring an enhanced understanding about the manner in which findings from research are presented and discussed.

\subsection{Research Findings}

The findings from this literature-based research have been divided into themes related to the understanding of RL and talent retention.

\subsection{Responsible Leadership and Talent Retention}

Research has indicated that employees tend to respond in a positive manner to the behaviour of leaders who are largely oriented towards employees. When leaders exhibit pro-employee behaviour, it tends to influence the turnover intention of employees (Jaramillo et al., 2009). Researchers have investigated the impact of diverse value-based leadership approaches such as ethical (Brown \& Treviño, 2006b), transformational (Avolio et al., 2004), authentic (Hirst et al., 2016) and servant leadership on talent retention. The common link between the findings from these studies is the manner in which the leaders within organisations are known to engage and encourage employees to such a level that it is less likely for the employee to think about quitting the organisation.

Waldman and Galvin (2008) suggested that by applying a social identity theory, a responsible leader would be in the position to connect with his followers by exhibiting actions that are responsible with each and every stakeholder. By adopting a RL approach, followers would be in a position to acquire entry or membership within the 'in' group, thereby augmenting attachment and loyalty to a responsible leader as well as the organisation. An increment in engagement and sense of belonging as well as attachment to the 'in' group within the circle of leadership has the scope to lower the turnover intention of employees.

\subsection{Responsible Leadership and Employee Autonomous Motivation}

Gagné and Deci (2005) proposed that RL augments autonomous motivation amongst employees. The findings from their research revealed that with regards to autonomous motivation, employees are known to frequently be involved in activities that correspond with their inner self. Activities of such kind essentially comprise of those that are at par with their goals and values and are pleasant as well as interesting. From an organisational point of view, responsible leaders tend to pass on their values by offering exemplary role models, while displayed values are internalised by employees on the basis of perceptual learning and observation. Ruyi and Lirong (2017) found that such internalisations could 
augment the self-expression of employees. RL that is more focused towards the responsibility of individuals towards societal and environmental well-being and the environment might dovetail objectives associated with sustainable management. For instance, it might elucidate environment-based objectives by stressing high-level values that (such as developing or working towards developing a better place for the coming generation, undertaking initiatives to enhance the health of people). Employees would be in a position to embrace as well as internalise such values that have been projected by responsible leaders; thus, their engagement in activities that revolve around the environment is rendered highly meaningful (Bono \& Judge, 2003). In addition, a leader who is responsible would motivate employees to take part in decision-making and make it known (amongst employees) that the organisation values their feedback and opinions. This presents employees with a semblance of psychological ownership that caters to their intrinsic requirements and encourages them to execute their jobs in the best manner possible.

\subsection{Talent Retention and Organisational Performance}

Any organisation is expected to make investments towards the retention of employees with a view to achieve success (Mendes \& Stander, 2011). Organisations are often unsuccessful in retaining their talent. As such, they are expected to develop suitable strategies that facilitate talent retention. Ma and Trigo (2008) found that retention serves to motivate employees to continue to be employed within an organisation for a long period of time. The reason is that when talented employees leave an organisation, the costs related to recruiting other talented employees becomes high for any organisation. Apart from direct costs such as costs associated with attracting talent, transition and training, there are also indirect costs linked with a drop in production, lower levels of performance, unwarranted overtime, and very low levels of morale.

Chikumbi (2011) initially conducted a literature review which was later complimented by an empirical investigation. The findings from both methods were compared to assess if there was any variation between the findings from the review of literature and the practices pertaining to talent retention within Zambian banks. This study revealed that in order to ensure success within talent retention, it was imperative to plan the organisational goals with the help of succession planning. Nonetheless, workers often complained that the reward and remuneration system was largely biased, leaving a large number of employees harbouring the feeling that their career prospects were jeopardised. This led to high employee turnover which had a negative impact on the performance of the organisation. In addition, employees lacked a clear perception of the culture of the organisation which made it difficult for them to adhere to the cultural codes.

Another study by Domfeh (2012) attempted to understand the impact of talent retention on the performance of rural banks in Ghana. The study revealed that talent retention enabled rural banks to ensure loyalty amongst customers owing to long term association between employees and customers. Clients and customers engaged or continued to engage in business with an organisation, in part due to the employees within an organisation. A long-term employee has more scope to build trust and develop a relationship that fosters a continuous business sponsorship. In the event that an employee leaves the organisation, the relationship and trust that was developed by the employee for the organisations is terminated and, in many instances, the replacement might not be as friendly as the previous employee. Thus, the study indicated that employee retention can enhance organisational performance through the delivery of service.

\subsection{Discussion and Conclusion \\ 6.1 Discussion}

Responsible actions that are desired and supposedly initiated by leaders which could effectively tackle the requirements of the stakeholders can be instrumental in enhancing the level of organisational commitment of the followers who expect this kind of responsible behaviour on the part of their leaders (Doh \& Quigley, 2014). Such followers have more scope to possess enhanced levels of attraction and attachment to such leaders as well as their organisations. Attractions and attachments of this kind, on the part of the followers, would play a key role in lowering any uncertainty that employees might have regarding their work role, and this would also be beneficial in augmenting positive attitudes towards their work roles (Voegtlin et al., 2012). In such a scenario, leading in a manner which is responsible has 
more propensity to lower the intention of turnover which, amongst other outcomes, also results in enhancing organisational commitment and offering employee cost-benefits to the organisation. Therefore, scrutinising the association of RL in terms of organisational commitment might provide useful insights with regards to the turnover intention in situations where turnover has been introduced as a mediating influence (Antunes \& Franco, 2016).

This literature review-based research paper deliberates about whether RL influences employee retention. The findings derived on the basis of this review indicate that RL does influence employee retention in a positive manner. This finding is clearly supportive of the findings presented by Chitra (2013) who stated that RL could have a positive influence on the retention of employees within an organisation. Chitra (2013) added that responsible leaders tended to develop a climate of retention within the organisation to facilitates employees to conclude that they are an integral part of an organisation. Further, this would motivate them to remain in their employment for a longer period of time. Similarly, they also found that there was a positive link between RL and employee retention as leaders tended to communicate and be interested in including employees within every activity.

Another major finding of this research is the link between talent retention and organisational performance. In particular, the study revealed that there was a positive and close association between talent retention and organisational performance. Talent retention improves the performance of the organisation in several ways. This finding was in tandem with the findings presented by Domfeh (2012), indicating that talent retention had several effects on organisational performance in myriad ways wherein one impact was that organisations gained operational efficiency. The research found that employees who were engaged with an organisation for a longer period of time, on the basis of their experience, were able to provide exceptional services to customers in shorter time spans. This reduced the queues at the bank being investigated and increased overall turnaround time, thereby improving organisational performance. The finding from this research also found that there was a close association between RL and employees' autonomous encouragement. The findings from a study by Sougui et al. (2016) revealed that RL encouraged employees by enabling them to concentrate on a higher cause.

\subsection{Conclusion}

On the basis of the review of literature, it can be concluded that RL does play an intrinsic role in influencing employee retention within organisations. The findings have clearly indicated that if responsible leaders ensure that employees are kept encouraged, this will not only facilitate the retention of talent, but will also increase the productivity of the organisation. Further, from the findings of this research it can also be concluded that RL influences talent retention within organisations. All the literature that has been included within this review reported an inverse association amongst RL and talent retention. The intention of the employee to leave was found to be the favoured measure that was commonly utilised across diverse studies to evaluate retention and turnover rates. In situations where there is a lack of responsible leaders, it has been observed that the intention of employees to leave increases. The converse is true. When leadership is responsible, the intention to leave decreases.

\subsection{Limitation and Recommendations for Future Research}

While this research involved an extensive literature review to achieve the aim of this research and provided some credible results, it is subject to several limitations that are inherent in a secondary research. The major limitation is that the findings have been gathered from various studies that employed a myriad of methods, involving varied samples and industries. As such, there is no clarity whether these findings can be applied across all industry sectors. Thus, the findings have not been derived specifically from one particular industry or a specific sample or a specific methodology. In order to gain a more detailed insight into this topic and derive a first-hand experience, in future an empirical research over a specific industry needs to be conducted to narrow down the results.

\subsection{Recommendation for Practitioners}

There is adequate research pertaining to employee identification and their satisfaction with an organisation. These aspects have not been covered within this research. Addressing these variables in order to augment the pride and satisfaction of employees could also be a feasible strategy to enhance talent retention within organisations (Doh et al., 2011). 


\section{References}

Allen, D.G., Bryant, P.C. \& Vardaman, J.M. (2010). Retaining Talent: Replacing Misconceptions With Evidence-Based Strategies. Academy of Management Perspectives, 24(2), pp. 48-64.

Antunes, A. \& Franco, M. (2016). How people in organizations make sense of responsible leadership practices. Leadership \& Organization Development Journal, 37(1), pp. 126-152.

Aurifeille, J.-M., Medlin, C., Tisdell, C., Gil Lafuente, J. \& Aluja, J. (2011). Globalisation, Governance and Ethics: The Main Issues. In: Globalisation, Governance and Ethics: New Managerial and Economic Insights. [Online]. Available from:

https://www.researchgate.net/publication/256996505_Globalisation_Governance_and_Ethics_The_Main_Issues.

Avolio, B.J., Zhu, W., Koh, W. \& Bhatia, P. (2004). Transformational leadership and organizational commitment: mediating role of psychological empowerment and moderating role of structural distance. Journal of Organizational Behavior, 25(8), pp. 951-968.

Bandura, R.P. and Lyons, P.R. (2014). Short-term fixes fall short when it comes to keeping the best employees. Human Resource Management International Digest, 22(5), pp. 29-32.

Bartram, P. (2012). 8 ways to... retain talent. Financial Management. pp. 36. Available from: http://connection.ebscohost.com/c/articles/83631512/8-ways-to-retain-talent.

Bass, B.M. \& Avolio, B.J. (1994). Improving organizational effectiveness through transformational leadership. London: Sage Publications.

Baumeister, R.F. \& Leary, M.R. (1997). Writing narrative literature reviews. Review of General Psychology, 1(3), pp. 311320.

Berson, Y. \& Linton, J.D. (2005). An examination of the relationships between leadership style, quality, and employee satisfaction in R\&D versus administrative environments. $R$ and $D$ Management, 35(1), pp. 51-60.

Bhattacharya, C.B., Sen, S. \& Korschun, D. (2008). Using corporate social responsibility to win the war for talent. MIT Sloan management review, 49(2), pp. 37-44

Bono, J.E. \& Judge, T.A. (2003). Self-Concordance at Work: Toward Understanding the Motivational Effects of Transformational Leaders. Academy of Management Journal, 46(5), pp. 554-571.

Brown, M.E. \& Treviño, L.K. (2006a). Ethical leadership: A review and future directions. The Leadership Quarterly, 17(6), pp. 595-616.

Brown, M.E. \& Treviño, L.K. (2006b). Ethical leadership: A review and future directions. The Leadership Quarterly, 17(6), pp. 595-616.

Caldwell, C. \& Dixon, R.D. (2010). Love, Forgiveness, and Trust: Critical Values of the Modern Leader. Journal of Business Ethics, 93(1), pp. 91-101.

Cappelli, P. (2008). Talent management for the twenty-first century. Harvard Business Review, 86(3), pp. 74.

Chambers, E.G., Foulon, M., Handfield-Jones, H., Hankin, S. \& Michaels, E. (1998). The War for Talent. The McKinsey Quarterly, 3, pp. 44-57.

Chikumbi, C.N.L. (2011). An investigation of talent management and staff retention at the bank of Zambia. PhD. Nelson Mandera Metropolitan University.

Chitra, M.K. (2013). Role of leaders in employee retention A pragmatic study with reference to private sector bank employees. International Research Journal of Business and Management, 6(1), pp. 65-74.

Cismas, S.C., Dona, I. \& Andreiasu, G.I. (2016). Responsible Leadership. Procedia - Social and Behavioral Sciences, 221(5), pp. 111-118.

Cowin, L. (2002). The Effects of Nurses' Job Satisfaction on Retention. The Journal of nursing administration, 32(5), pp. 283-291.

D'Amato, A., Henderson, S. \& Florence, S. (2009). Corporate Social Responsibility and Sustainable Business: A Guide to Leadership Tasks and Functions. [online] Center for Creative Leadership. Available at: https://books.google.co.in/books?id=Qx1cPgAACAAJ.

Das, B.L. \& Baruah, M. (2013). Employee retention: A review of literature. Journal of Business and Management, 14(2), pp. 8-16.

Doh, J.P. \& Quigley, N.R. (2014). Responsible Leadership and Stakeholder Management: Influence Pathways and Organizational Outcomes. Academy of Management Perspectives, 28(3), pp. 255-274.

Doh, J.P., Stumpf, S.A. \& Tymon, W.G. (2011). Responsible Leadership Helps Retain Talent in India. Journal of Business Ethics, 98(S1), pp. 85-100.

Domfeh, R. O (2012). An examination of the effects of employee retention strategies on the performance of selected Rural Banks in Ashanti Region. [online] Available at: http://dspace.knust.edu.gh/handle/123456789/7690.

Fernando, M. (2015). Leading Responsibly in the Asian Century. [online]. Springer International Publishing. Available at: https:/ / books.google.co.in/books?id=bCg3CwAAQBAJ.

Filatotchev, I. (2012). Corporate governance issues in competitive strategy research. Handbook of Research on Competitive Strategy, [online]. pp. 300-324. Available at: 
https://www.researchgate.net/publication/285951109_Corporate_governance_issues_in_competitive_strateg y_research.

Flocy, J. (2017). Responsible leadership: A behavioural perspective. [online]. Singapore Management University. Available at: http://ink.library.smu.edu.sg/cgi/viewcontent.cgi?article=1008\&context=etd_coll_all.

Gagné, M. \& Deci, E.L. (2005). Self-determination theory and work motivation. Journal of Organizational Behavior, 26(4), pp. 331-362.

Gardner, W.L., Avolio, B.J., Luthans, F., May, D.R. \& Walumbwa, F. (2005). “Can you see the real me?” A self-based model of authentic leader and follower development. The Leadership Quarterly, 16(3), pp. 343-372.

Gharibvand, S., Mazumder, M.N.H., Mohiuddin, M. \& Su, Z. (2013). Leadership Style and Employee Job Satisfaction: Evidence from Malaysian Semiconductor Industry. Transnational Corporations Review, 5(2), pp. 93-103.

Greenleaf, R.K., Spears, L.C. \& Covey, S.R. (2002). Servant Leadership: A Journey Into the Nature of Legitimate Power and Greatness. [online] Paulist Press. Available at: https://books.google.co.in/books?id=AfjUgMJIDK4C.

Guthridge, M., Komm, A.B. \& Lawson, E. (2008). Making talent a strategic priority. McKinsey Quarterly, 1, pp. 48.

Gwavuya, F. (2011). Leadership influences on turnover intentions of academic staff in tertiary institutions in Zimbabwe. Academic Leadership. [online] Researchgate. Available at:

https://www.researchgate.net/publication/289574557_Leadership_influences_on_turnover_intentions_of_ac ademic_staff_in_tertiary_institutions_in_Zimbabwe.

Hirst, G., Walumbwa, F., Aryee, S., Butarbutar, I. \& Chen, C.J.H. (2016). A Multi-level Investigation of Authentic Leadership as an Antecedent of Helping Behavior. Journal of Business Ethics, 139(3), pp. 485-499.

Holtom, B.C., Mitchell, T.R., Lee, T.W. \& Inderrieden, E.J. (2005). Shocks as causes of turnover: What they are and how organizations can manage them. Human Resource Management, 44(3), pp. 337-352.

Ibidunni, S., Osibanjo, O., Adeniji, A., Salau, O.P. \& Falola, H. (2016). Talent Retention and Organizational Performance: A Competitive Positioning in Nigerian Banking Sector. Periodica Polytechnica Social and Management Sciences, 24(1), pp. 1-13.

Jaramillo, F., Grisaffe, D.B., Chonko, L.B. \& Roberts, J.A. (2009). Examining the Impact of Servant Leadership on Salesperson's Turnover Intention. Journal of Personal Selling E Sales Management, 29(4), pp. 351-365.

Jin, M.H., McDonald, B. \& Park, J. (2018). Person-Organization Fit and Turnover Intention: Exploring the Mediating Role of Employee Followership and Job Satisfaction Through Conservation of Resources Theory. Review of Public Personnel Administration, 38(2), pp. 167-192.

Kakabadse, N.K., Rozuel, C. \& Lee-Davies, L. (2005). Corporate social responsibility and stakeholder approach: a conceptual review. International Journal of Business Governance and Ethics, 1(4), pp. 277.

Kapur, R. (2018a). Ethical Leadership. [online] Researchgate. Available at: https://www.researchgate.net/publication/323829602_Ethical_Leadership.

Kapur, R. (2018b). Organization Development. [online] Researchgate. Available at: https://www.researchgate.net/publication/323825290_Organization_Development.

Kim, W.G. \& Brymer, R.A. (2011). The effects of ethical leadership on manager job satisfaction, commitment, behavioral outcomes, and firm performance. International Journal of Hospitality Management, 30(4), pp. 10201026.

Kleinman, C. (2004). The Relationship between Managerial Leadership Behaviors and Staff Nurse Retention. Hospital Topics, 82(4), pp. 2-9.

Kossivi, B., Xu, M. \& Kalgora, B. (2016). Study on determining factors of employee retention. Open Journal of Social Sciences, 4(05), pp. 261.

Kotter, J.P. (1990). Force For Change: How Leadership Differs from Management. New York: The Free Press.

Low, M.P., Ong, S.F. \& Tan, P.M. (2017). Would internal corporate social responsibility make a difference in professional service industry employees' turnover intention? A two-stage approach using PLS-SEM. Global Business and Management Research, 9(1), pp. 24.

Ma, S. \& Trigo, V. (2008). Winning the War for Managerial Talent in China: An Empirical Study. The Chinese Economy, 41(3), pp. 34-57.

Maak, T. \& Pless, N.M. (2006). Responsible Leadership in a Stakeholder Society - A Relational Perspective. Journal of Business Ethics, 66(1), pp. 99-115.

Maak, T. \& Pless, N.M. (2009). Business Leaders as Citizens of the World. Advancing Humanism on a Global Scale. Journal of Business Ethics, 88(3), pp. 537-550.

Maak, T., Pless, N.M. \& Voegtlin, C. (2016). Business Statesman or Shareholder Advocate? CEO Responsible Leadership Styles and the Micro-Foundations of Political CSR. Journal of Management Studies, 53(3), pp. 463493.

Maamari, B.E. \& Alameh, K. (2016). Talent Management Moderating the Relationship between Recruitment for the Highly Skilled and HR Policies. Contemporary Management Research, 12(1), pp. 121-138. 
Maritz, R., Pretorius, M. \& Plant, K. (2011). Exploring the Interface Between Strategy-Making and Responsible Leadership. Journal of Business Ethics, 98(S1), pp. 101-113.

Mendes, F. \& Stander, M.W. (2011). Positive organisation: The role of leader behaviour in work engagement and retention. SA Journal of Industrial Psychology, 37(1),

Meyer, J.P., Stanley, D.J., Herscovitch, L. \& Topolnytsky, L. (2002). Affective, Continuance, and Normative Commitment to the Organization: A Meta-analysis of Antecedents, Correlates, and Consequences. Journal of Vocational Behavior, 61(1), pp. 20-52.

Mir, A.A. \& Mufeed, U. (2016). Employee Retention-A Key Tool for Achieving Competitive Advantage. International Journal of Engineering and Management Research (IJEMR), 6(6), pp. 334-337.

Miska, C. \& Mendenhall, M.E. (2018). Responsible Leadership: A Mapping of Extant Research and Future Directions. Journal of Business Ethics, 148(1), pp. 117-134.

Netswera, F.G., Rankhumise, E.M. \& Mavundla, T.R. (2005). Employee Retention Factors For South African Higher Education Institutions: A Case Study. SA Journal of Human Resource Management, 3 (3).

Northouse, P.G. (2018). Leadership: Theory and practice. London: Sage publications.

Owie, E. (2017). The Imperative of the Corporation and Socially Conscious Leadership. Journal of Social Change, 9(1), pp. 141-149.

Phillips, R., Freeman, R.E. and Wicks, A.C. (2003). What stakeholder theory is not. Business Ethics Quarterly, 13(4), pp.479-502.

Pless, N. \& Maak, T. (2004). Building an inclusive diversity culture: Principles, processes and practice. Journal of Business Ethics, 54(2), pp. 129-147.

Pless, N.M. \& Maak, T. (2011). Responsible Leadership: Pathways to the Future. Journal of Business Ethics, 98(S1), pp. 3-13.

Rasmussen, E. \& Hunt, V. (2007). Turnover and retention in a tight labour market: reflecting on New Zealand research. [online] Researchgate. Available at:

https://www.researchgate.net/publication/228353558_Turnover_and_retention_in_a_tight_labour_market_reflectin g_on_New_Zealand_research.

Rodriguez-Fernandez, M. (2016). Social responsibility and financial performance: The role of good corporate governance. BRQ Business Research Quarterly, 19(2), pp. 137-151.

Ruyi, Z. \& Lirong, L. (2017). Self-sacrificial Leadership: A literature Review and Prospects. Foreign Economics $\mathcal{E}$ Management, 39(11), pp. 77-89.

Siegel, D.S. (2014). Responsible Leadership. Academy of Management Perspectives, 28(3), pp. 221-223.

Simiyu, A. (2015). Role of Leadership In Organizational Development. [online] Researchgate. Available at: https://www.researchgate.net/publication/273766248_ROLE_OF_LEADERSHIP_IN_ORGANIZATIONAL_ DEVELOPMENT.

Snyder, H. (2019). Literature review as a research methodology: An overview and guidelines. Journal of Business Research, 104, pp. 333-339.

Sougui, A., Bon, A., Mahamat, M. \& Hassan, H. (2016). The Impact of Leadership on Employee Motivation in Malaysian Telecommunication Sector. Galore International Journal of Applied Sciences and Humanities, 1(1), pp. 5968.

Stahl, G. \& Sully de Luque, M. (2014). Antecedents of responsible leader behavior: A research synthesis, conceptual framework, and agenda for future research. Academy of Management Perspectives, 28(3), pp. 235-254.

Thomas, D.A. (2004). Diversity as Strategy. Human Resource Management, [Online]. Harvard Business Review. Available from: https://hbr.org/2004/09/diversity-as-strategy.

Tranfield, D., Denyer, D. \& Smart, P. (2003). Towards a methodology for developing evidence informed management knowledge by means of systematic review. British Journal of Management, 14(3), pp. 207-222.

Voegtlin, C., Patzer, M. \& Scherer, A.G. (2012). Responsible Leadership in Global Business: A New Approach to Leadership and Its Multi-Level Outcomes. Journal of Business Ethics, 105(1), pp. 1-16.

Waldman, D.A. \& Balven, R.M. (2014). Responsible Leadership: Theoretical Issues and Research Directions. Academy of Management Perspectives, 28(3), pp. 224-234.

Waldman, D.A. \& Galvin, B.M. (2008). Alternative Perspectives of Responsible Leadership. Organizational Dynamics, 37(4), pp. 327-341.

Webster, J. \& Watson, R.T. (2002). Analyzing the Past to Prepare for the Future: Writing a Literature Review. MIS Quarterly, 26(2), pp. xiii-xxiii.

Witt, M.A. \& Stahl, G.K. (2016). Foundations of Responsible Leadership: Asian Versus Western Executive Responsibility Orientations Toward Key Stakeholders. Journal of Business Ethics, 136(3), pp. 623-638.

Woo, S.E., Chae, M., Jebb, A.T. \& Kim, Y. (2016). A Closer Look at the Personality-Turnover Relationship. Journal of Management, 42(2), pp. 357-385. 
Zhang, X. \& Bartol, K.M. (2010). Linking Empowering Leadership And Employee Creativity: The Influence Of Psychological Empowerment, Intrinsic Motivation, And Creative Process Engagement. The Academy of Management Journal, 53(1), pp. 107-128. 